\title{
Thromboprophylaxis in Radical Retropubic Prostatectomy: Efficacy and Patient Compliance of a Dual Modality
}

\author{
Luca Cindolo $^{\mathrm{a}}$ Luigi Salzano $^{\mathrm{a}}$ Vincenzo Mirone $^{\mathrm{b}}$ Ciro Imbimbo $^{\mathrm{b}}$

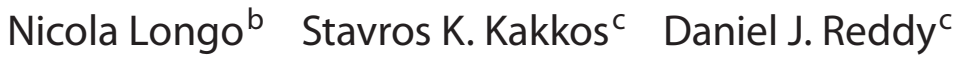 \\ a Urology Unit, 'G. Rummo' Hospital, Benevento, and b'Department of Urology, 'Federico II' University, Naples, Italy; \\ 'Division of Vascular Surgery, Department of Surgery, Henry Ford Hospital, Detroit, Mich., USA
}

\section{Key Words}

Intermittent pneumatic compression - Deep venous thrombosis - Pulmonary embolism - Thromboprophylaxis • Prostate cancer $\cdot$ Radical retropubic prostatectomy

\begin{abstract}
Objectives: The risk of developing venous thromboembolism (VTE) in urologic patients undergoing major surgery without thromboprophylaxis is high (up to $40 \%$ ). The aims were to study the acceptability rate of and overall patient satisfaction with an automatic sequential leg compression system and the short-term effectiveness of a combined VTE prevention modality. Methods: One-hundred and eightyfour consecutive patients undergoing radical retropubic prostatectomy were postoperatively treated with enoxaparine and intermittent pneumatic compression of the thigh. By completing a questionnaire, the patients were prospectively studied to evaluate the comfort and tolerability of a compression device (SCD Response Compression System; Covidien, Gosport, UK). The patients were monitored for complications and development of VTE for up to 4 weeks postoperatively. The device used ensures customized and effective compression therapy matching the patient's individual vascular refill by sequential, gradient, circumferential microprocessor-controlled compression cycles. Results: No
\end{abstract}

clinically evident VTE, critical bleeding or postoperative death occurred during the study period. Drain output was associated with transfusion requirement $(p<0.001)$, obesity $(p<0.02)$ and longer operation duration $(p<0.001)$. The sequential compression devices were well tolerated by $63 \%$ of the patients, in that the sleeves were judged as being pleasant (72\%) and nonoppressive (79\%). Patients reported bothersome insomnia (23\%) and noise (44\%), and early removal was required in $3 \%$. Conclusions: Combined mechanical and pharmacological thromboprophylaxis was highly effective, well tolerated, and safe. The device tested showed a high comfort and tolerability profile. The use of combined modalities for VTE prophylaxis is justified in patients at very high risk of VTE, such as those undergoing radical retropubic prostatectomy.

Copyright $\odot 2009$ S. Karger AG, Basel

\section{Introduction}

Pulmonary embolism (PE) is a leading cause of death among hospitalized patients, accounting for about $10 \%$ of hospital-related deaths. The risk of venous thromboembolism (VTE) overall is increasing because hospitalized patients today are older, have multiple comorbidities, and are undergoing more major surgical procedures. Among

\section{KARGER}

Fax +4161306 1234 E-Mail karger@karger.ch www.karger.com (c) 2009 S. Karger AG, Basel

0042-1138/09/0831-0012\$26.00/0

Accessible online at:

www.karger.com/uin
L. Cindolo, MD, FEBU

Urology Unit, ‘G. Rummo’ Hospital

Viale dell'Angelo, 1

IT-82100 Benevento (Italy)

Tel./Fax +390824 57477, E-Mail lucacindolo@virgilio.it 
hospitalized medical patients without VTE prophylaxis, the absolute risk of VTE is 10-20\% [1]. This risk is higher in surgery patients who have not received prophylaxis (range from 15\% to $>80 \%$ ) $[1,2]$. The risk of developing VTE in urologic patients undergoing major open or laparoscopic procedures without thromboprophylaxis varies between 10 and $40 \%[1,2]$.

Despite the prevalence of VTE among surgical patients, thromboprophylaxis has often been underutilized $[3,4]$. A survey of orthopedic surgeons showed that only $55 \%$ placed all patients on a VTE prophylactic regimen [3]. A Medicare study confirmed that only $38 \%$ of elderly patients undergoing abdominal or thoracic surgery received VTE prophylaxis [3]. A recent Italian survey showed that in-hospital thromboprophylaxis was given in about $72 \%$ of urologic patients (including endoscopic and open surgical procedures), whereas post-discharge prophylaxis was given in $32.5 \%$ of all cases [4]. The authors also reported the late occurrence of 1 VTE and 1 death in 111 radical prostatectomy patients after the discontinuation of pharmacologic thromboprophylaxis. Moreover, they described that only 5\% (35/685) of all urological patients were protected against the risk of thromboembolism using a combination of stockings with pharmacologic prophylaxis [4]. Moreover, the approach to VTE prophylaxis related to surgery for prostate cancer is one area in which practices differ markedly. It is interesting that the vast majority of European urologists (100\% in Great Britain and 50\% in Ireland) routinely prescribe the use of pharmacologic deep vein thrombosis and/or PE prophylaxis, whereas the wide majority (about 75\%) of North American urologists do not use pharmacologic prophylaxis unless patients are at the highest risk for VTE or PE [5].

Patients undergoing radical retropubic prostatectomy (RRP) had multiple risk factors for VTE (advanced age, malignancy, and pelvic surgery with or without lymph node dissection, duration of surgery, hypotension), and were classified as being at very high risk both by the NICE [1] and ACCP guidelines [2]. These guidelines recommended that mechanical prophylaxis should be offered to high-risk urologic surgical patients, adding a low-molecular weight heparin for the very high-risk patients [2].

Available methods for VTE prophylaxis include unfractionated or low-molecular weight heparin, graduated elastic compression stockings, lower extremity sequential compression devices (SCDs) and a combination of these. The rationale for low-molecular weight heparin use is well known $[1,2]$. The rationale for the use of a SCD is to enhance venous flow at the sites of vascular trauma or in areas of venous stasis. Specifically, the SCD Response Compression System (Tyco Healthcare/Covidien, Gosport, UK) ensures customized and effective compression therapy matching the patient's individual vascular refill [6]. Because thromboprophylaxis achieved by combined modalities (mechanical and pharmacological) is strongly recommended for patients at very high risk for VTE [1, 2], we decided to investigate and grade both the acceptability rate and overall satisfaction of the SCDs from a patient-oriented perspective. Additionally, we evaluated the short-term effectiveness of such a combined VTE prevention regimen in patients undergoing RRP for cancer.

\section{Patients and Methods}

Consecutive patients with clinically localized prostate cancer (T1-3, N0, M0) undergoing RRPs by 1 surgeon (L.S.) were considered candidates for inclusion in the present study. Exclusion criteria included advanced prostate cancer not suitable for RRP, clinically localized prostate cancer treated with modalities different than RRP, thrombocytopenia (platelet count $<60,000 / \mathrm{mm}^{3}$ ), coagulopathy (prolonged prothrombin time $>20 \mathrm{~s}$, or partial thromboplastin time $>45 \mathrm{~s}$ ), contraindications to SCD use (severe arteriosclerotic or other ischemic lower extremity vascular disease, suspected acute venous thrombosis, or previous pulmonary edema from congestive heart failure, extreme deformity of leg), use of oral anticoagulants, or inability to collaborate with the physician or nurses. Each patient had deep vein thrombosis risk assessment performed preoperatively according to the NICE and ACCP guidelines (table 1) $[1,2]$.

Patients routinely deposited 1 or 2 units of autologous blood 1-3 weeks before surgery, and were admitted the day before surgery. Thromboprophylaxis was based on a SCD that uses thighhigh sleeves (SCD Response Compression System, Tyco Healthcare/Covidien) and enoxaparine 4,000 IU s.c. $1 \mathrm{~h}$ prior to surgery, continuing postoperatively once daily until day 21; anti-embolism stockings were not used. Mechanical thromboprophylaxis was initiated immediately before RRP with the sleeves being placed on both lower extremities before inducing anesthesia. A standard RRP through a lower midline incision was performed. Bilateral iliac-obturator pelvic node dissection was performed. A pelvic drain was routinely inserted; drain output being measured upon tube removal. The compression system remained active night and day until full ambulation, which usually occurred on the 2nd day after RRP, with the patients being strongly encouraged to start ambulation. Early removal of the sleeves was defined as the suspension of compression during the 1st postoperative day. Correct functioning of the system and proper application of the sleeves were controlled several times each day. The patients and clinical staff (physicians, nursing staff) were informed of the need for compliance.

On postoperative day 1, all patients were given a structured questionnaire with six questions on parameters related to compli- 
Table 1. Levels of thromboembolism risk in surgical patients without prophylaxis

\begin{tabular}{lll}
\hline & Variables & Prophylactic strategies \\
\hline Low risk & $\begin{array}{l}\text { Minor surgery in patients }<40 \text { years } \\
\text { with no additional risk factors }\end{array}$ & $\begin{array}{l}\text { No specific prophylaxis; early } \\
\text { and 'aggressive' mobilization }\end{array}$ \\
\hline Moderate risk & $\begin{array}{l}\text { Minor surgery in patients }<40 \text { years } \\
\text { with additional risk factors; } \\
\text { Surgery in patients aged } 40-60\end{array}$ & FH, or GCS or IPC \\
& years with no additional risk factors & \\
\hline High risk & $\begin{array}{l}\text { Surgery in patients }>60 \text { or } 40-60 \\
\text { years with additional risk factors } \\
\text { (prior VTE, cancer, molecular } \\
\text { hypercoagulability) }\end{array}$ & FH or IPC \\
\hline Very high risk & $\begin{array}{l}\text { Surgery in patients with multiple } \\
\text { risk factors (age }>40 \text { years, cancer, } \\
\text { prior VTE) }\end{array}$ & $\begin{array}{l}\text { FH, fondaparinux, oral VKAs } \\
\text { (INR 2-3), or IPC/GCS + FH }\end{array}$ \\
\hline
\end{tabular}

$\mathrm{FH}=$ Fractioned heparin; VKA = vitamin $\mathrm{K}$ antagonists; $\mathrm{IPC}=$ intermittent pneumatic compression; GCS = graduated compression stockings. Modified from Geerts et al. [2]. ance with the SCD (see Appendix), and also patient willingness to discontinue using the SCD, based on their answers to these six questions. This questionnaire used a four-grade scale to investigate tolerability, pleasantness, oppressive sensation, and the noise level of the device, and also the presence of dyspnea and insomnia as a result of using the device.

The presence of VTE events during hospitalization was noted. Suspected postoperative PE was investigated by performing pulmonary CT angiogram. Color-coded duplex ultrasound was performed in the case of suspected deep venous thrombosis. Patients were usually discharged on enoxaparin 4 or 5 days after the RRP, and the Foley catheter was removed after 10-12 days. Following discharge from hospital patients were advised to continue the dorsiflexion exercises started in the afternoon of the surgery, to elevate their legs when sitting, and to walk frequently. Patients had their first postoperative visit at 4 weeks, or earlier if necessary. If there was clinical suspicion of deep vein thrombosis, lower extremity venous ultrasound was performed. Patients were seen at 3,6 and 9 months, and at 6-month intervals thereafter, for oncological and functional follow-up.

\section{Statistical Analysis}

All data were entered into a Microsoft Office Excel database (Microsoft Inc., Redmond, Wash, USA) and analyzed with SPSS 14.0 for Windows (SPSS Inc., Chicago, Ill., USA). Factor analysis (principal component analysis using the Varimax rotation method with Kaiser normalization) was used to determine which questionnaire variables were interrelated (carried the same information). Categorical data were analyzed with the $\chi^{2}$ or Fisher's exact test, where appropriate; numerical data were analyzed using the $t$ test or Mann-Whitney test, where appropriate. A p value of $<0.05$ was considered as statistically significant. Two-tailed statistical tests were always used.

\section{Results}

During a 27-month period (February 2004 to April 2006 inclusive) a total of 190 patients underwent RRP. We excluded 2 patients due to psychosis and 4 because they were on oral anticoagulants, which left 184 patients in the study. Patient characteristics are shown in table 2. Our population was very homogenous for indication (clinically locally confined prostate cancer), age, type and duration of anesthesia (general anesthesia in $95.5 \%$; all procedures lasted more than $120 \mathrm{~min}$ ), standard preoperative and postoperative management from the same team. All 184 patients (100\%) were classified as being at very high risk for postoperative VTE due to the presence of multiple risk factors (pelvic surgery in $100 \%$, age $>40$ year in $100 \%$, malignancy in $100 \%$, long duration of anesthesia in $12 \%$, active smoking in $28 \%$, obesity in $29 \%$, presence of varicose vein in 14\%).

There was no operative or postoperative mortality. Intraoperative or excessive postoperative bleeding was not encountered, with a mean drain output of $228 \pm 104$ (range 40-600) $\mathrm{ml}$. The heterologous and autologous blood transfusion rate was 5.4 and $38 \%$, respectively; there was a significant association between drain output and transfusion requirement (fig. 1; all p $<0.001$ ). Median (interquartile range, IQR) drain output in patients with obesity was $250(200-300) \mathrm{ml}$, compared to 210 $(140-270) \mathrm{ml}$ in non-obese patients $(\mathrm{p}=0.02)$. Median 


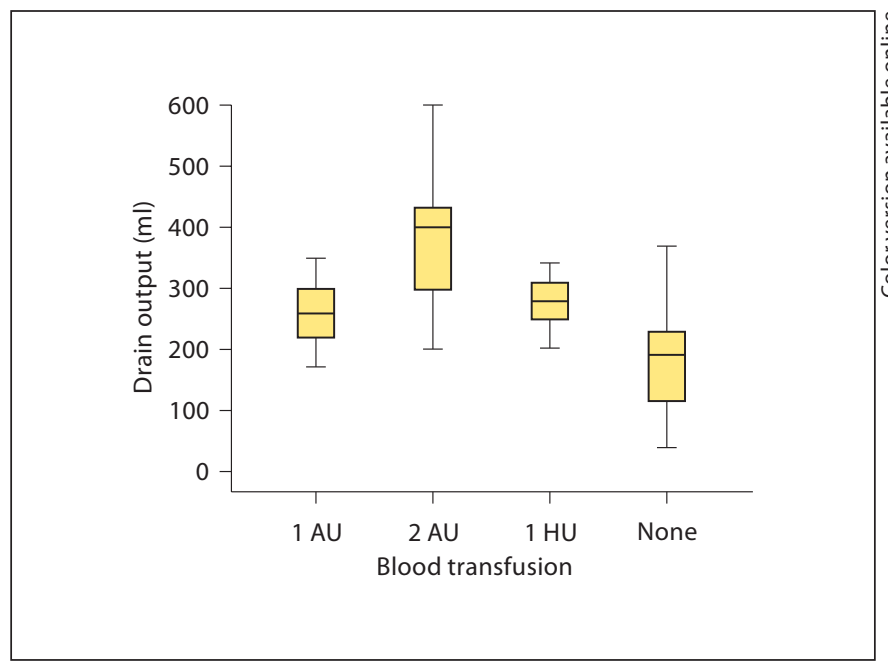

Fig. 1. Relationship between drain output and need for blood transfusion. $\mathrm{AU}=$ Autologous unit; $\mathrm{HU}=$ heterologous unit.

(IQR) drain output in patients with an operative duration of $>3 \mathrm{~h}$ was 305 (285-410) $\mathrm{ml}$, compared to $210(140-263)$ $\mathrm{ml}$ in patients with operative duration of $<3 \mathrm{~h}(\mathrm{p}<0.001)$. Median (IQR) drain output in patients who requested early removal of the SCD (see below) was $165(108-218)$ $\mathrm{ml}$, compared to $230(170-290) \mathrm{ml}$ in patients who did not require early removal of the $S C D(p=0.11)$. Up to week 4 postoperatively, no patient developed VTE.

The factor analysis results of the questionnaire are shown in table 3 . This revealed that questions on tolerability, pleasantness and oppressive sensation carried the same information. The same was the case for those questions on the noise level of the device and insomnia. The SCDs were well tolerated by $63 \%$ of the patients $(10 \%$ were completely unsatisfied). Moreover, the sleeves were judged pleasant and nonoppressive by 72 and $79 \%$ of the patients, respectively (fig. 2). Patients who were not able to tolerate the device at all were significantly older (median age 72, IQR 70-77 years) than the remainder (median age 69, IQR 65-72 years; $p=0.003$ ). Forty-three subjects $(23 \%)$ reported bothersome insomnia. Eighty-one patients (44\%) reported that the SCD caused a bothersome noise. Six patients (3\%) requested early removal of the sleeves during the 1st postoperative day mainly (66\%) because they could not tolerate the noise that the device made. These patients were significantly older than those who did not have their device removed (74, IQR 70-77 years, and 69, IQR 66-72 years, respectively; $\mathrm{p}=0.046$, Mann-Whitney test). Early removal was associated with low tolerability and unpleasantness, oppressive sensation

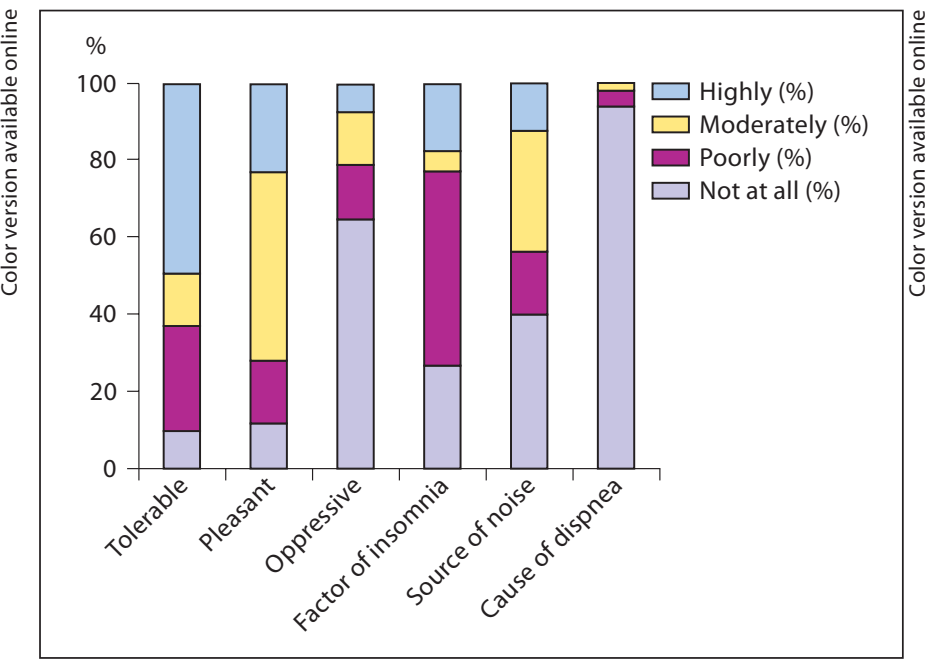

Fig. 2. Answers (\%) to the question 'Do you consider this device ....

Table 2. Patient characteristics

\begin{tabular}{lc}
\hline Mean age, years & $69 \pm 4.1$ \\
Clinical stage & \\
T1 & $106(58 \%)$ \\
T2 & $68(37 \%)$ \\
T3 & $10(5 \%)$ \\
Subjects at very high risk for VTE & $184(100 \%)$ \\
Smokers & $52(28 \%)$ \\
Obesity (BMI >25) & $55(30 \%)$ \\
Varicose veins & $27(15 \%)$ \\
ASA class & \\
1 & $6(3 \%)$ \\
2 & $101(55 \%)$ \\
3 & $66(36 \%)$ \\
4 & $11(6 \%)$ \\
Type of anesthesia & \\
General & $175(95.5 \%)$ \\
Spinal supplemented by sedation & $9(4.5 \%)$ \\
Duration of anesthesia & \\
$\quad<180$ min & $162(88 \%)$ \\
$>180$ min & $22(12 \%)$ \\
SCD activity time & $6(3 \%)$ \\
Until postoperative day 1 & $159(87 \%)$ \\
Until postoperative day 2 & $19(10 \%)$ \\
Until postoperative day 3 & \\
\hline
\end{tabular}

Unless otherwise indicated the values are the number of patients with percentages in parentheses. VTE = Venous thromboembolic events; ASA = American Society of Anesthesiology; $\mathrm{SCD}=$ sequential compression device; $\mathrm{BMI}=$ body mass index. 
Table 3. The rotated component matrix derived from factor analysis (principal component analysis using the Varimax rotation method with Kaiser normalization)

\begin{tabular}{lcc}
\hline Parameter & \multicolumn{2}{c}{ Component } \\
\cline { 2 - 3 } & 1 & 2 \\
\hline Tolerability & $\mathbf{0 . 9 2 9}$ & -0.028 \\
Pleasantness & $\mathbf{0 . 8 5 6}$ & -0.211 \\
Oppressive sensation & $\mathbf{0 . 8 5 7}$ & -0.035 \\
Insomnia & -0.145 & $\mathbf{0 . 8 5 2}$ \\
Noise & -0.200 & $\mathbf{0 . 8 1 6}$ \\
Dyspnea & -0.108 & -0.137 \\
\hline
\end{tabular}

Rotation converged in 3 iterations. Parameters in bold carry the same information, i.e. tolerability, pleasantness and oppressive sensation are highly intercorrelated and similar to insomnia with noise.

and insomnia $($ all $\mathrm{p}<0.001)$ but not the noise level or dyspnea ( $\mathrm{p}=0.33$ and 0.10 , respectively).

Discrete dyspnea occurred in $3 \%$ of the patients and exclusively in those with preoperative ASA class 3 and 4 $(\mathrm{p}<0.001)$; PE was excluded with pulmonary CT angiogram.

\section{Discussion}

VTE is considered to be one of the most critical and potentially fatal complications after major urological procedures [2]. Most of the epidemiological studies on the risk of VTE in urologic populations were performed in the early 1970s [7-9]. Subsequent changes in surgical options (laparoscopy, mini-invasive techniques, endourology), nurse care, early ambulation protocols, and possibly wide use of prophylaxis reduced the rates of VTE $[2,3,10]$. Nearly all hospitalized patients have some risk factors for VTE. Specifically patients undergoing major urologic surgery (like RRP) have multiple risk factors as confirmed by the current series.

Despite the variety of safe and effective pharmacologic and nonpharmacologic thromboprophylactic methods available nowadays, these are sometimes underutilized in the real world $[3,4,11,12]$ for a variety of reasons including issues with bleeding, severe peripheral occlusive disease, patient compliance and physician education. Although pharmacologic methods seem to be associated with a small risk of bleeding complications, it is well known that prophylactic administration of low-dose un- fractionated heparin, low-molecular weight heparin, or a vitamin $\mathrm{K}$ antagonist does not increase the rates of clinically important bleeding [2]. In fact, in our experience the mean output drain and the blood transfusion rates (almost exclusively autologous blood) were consistent with larger series.

On the other hand, mechanical methods have no associated bleeding risk $[1,2]$, but graduated compression stockings are considered uncomfortable $[1,2]$, and the foot pump, although tolerated better than compression devices [13], has poor patient compliance $[14,15]$ and relevant variability in VTE prevention efficacy $[15,16]$. In a unique randomized clinical trial evaluating the patient's view about mechanical thromboprophylaxis with a foot pump or SCD, no significant differences were found among the 2 groups with regard to comfort, but a wide range of responses was reported [17]. Recent evidence suggests that combined modalities were more effective than single modalities in VTE prophylaxis, endorsing the concept of the need for multimodality prophylaxis in high-risk patients $[2,18,19]$.

We developed and used a non-validated original questionnaire in order to investigate the comfort and tolerability of the device from a patient-oriented perspective. An overall favorable applicability of the thromboprophylaxis multimodal prevention strategy was found which was probably related to the high comfort and tolerability profile of the SCD Response Compression System Tyco Healthcare devices. The majority of our patients gave an overall positive opinion about the procedure and the device, especially when a good relationship with the caregivers (surgeons and nurses) was established [1-20]. Silbersack et al. [21] and Maxwell et al. [22] reported an high rate (27\%) of premature discontinuation of intermittent pneumatic compression and a not negligible (26\%) percentage of patients being disturbed by the pneumatic compression; in contrast in our series we found that the majority of patients accepted the SCD sleeves and only a small percentage (3\%) did not tolerate the pneumatic compression, requiring early removal. These discrepancies could be explained by the different pneumatic compression devices; the different postoperative mobilization protocol, and the different surgical specialty (i.e. orthopedic vs. abdominal). In the present study about a quarter of all patients consider the SCD as a factor of insomnia. Considering the mean age of our population (69 \pm 4.1 years) and the prevalence of short 'hours of undisturbed sleep' related to the lower urinary tract symptoms (notably nocturia) [23, 24], the recorded rate of men suffering from insomnia (23\%) appears not surprising. 
Moreover, the diagnosis of prostate cancer and its treatments (surgery and radiation therapy) are considered a cause of insomnia itself [25]. In fact, the prevalence of insomnia in the prostate cancer population after diagnosis is about 30 [25] versus $23 \%$ recorded in the present study. Based on these findings, we do not think that the use of the SCD Response Compression System increases the prevalence of insomnia in the subset of hospitalized and operated patients, and encourage the use of ear plugs or a narcotic in these patients.

Forty percent of the patients did not complain about the compressor noise at all, whereas another $44 \%$ reported a moderate $(32 \%)$ to high (12\%) noise level. The data on noise should be critically evaluated. Even if there is room for improvement in noise production by the compressor, we believe that the device itself did not disturb our patients' sleep and did not represent a relevant cause of early removal of the sleeves. The comparison of noise perception between groups (moderate to high versus poor to not at all groups) did not reach statistical significance $(\mathrm{p}>0.10)$, probably because what the patient referred to was considered postsurgical impatience (combination of noise, insomnia and low tolerability). As reported by others, we found that $4 / 6$ subjects among those requiring the early discontinuation of the compression attributed it to the noise. This is consistent with the few data from the literature showing that sleep disturbances attributed to noise was the more frequent reason (69$81 \%)$ for premature termination [16-26].

Finally, as previously suggested, we confirm that thromboprophylaxis achieved by combined modalities (sequential compression and enoxaparine) is reliable, effective and safe $[18,21]$, even if in a randomized clinical setting. Herein, we show that the tested devices demonstrated a high comfort and tolerability profile.

Considering that (i) Ramirez et al. [27] in a different population considered prophylaxis for perioperative VTE solely with SCD as a 'viable option for patients classified as highest risk under ASCRS parameters'; (ii) the ACCP and the ASCO strongly encouraged the thromboprophylaxis [2, 28]; (iii) Roderick et al. [29] conclude their systematic review stating that physical methods (graduated compression stockings, intermittent pneumatic compression or foot pumps) reduced the risk of VTE by about two thirds when used as monotherapy and by about half when added to a pharmacological method, and (iv) the National Collaborating Centre for Acute Care [1] recommended that at least mechanical prophylaxis should be offered to patients undergoing major urological surgery, we suggest the routine use of this device in patients undergoing RRP, taking also into account the few contraindications, the absence of adverse potentially fatal events, its cost-effectiveness and the good tolerance profile.

Our study shows that in postoperative settings the majority of patients well tolerated the method of thromboembolism prophylaxis administered. In conclusion, external pneumatic compression associated with lowmolecular weight heparin can be easily provided with acceptable compliance and safety, justifying routine use after RRP.

\section{Acknowledgments}

We thank Teresa Giovanna Crisci for reviewing the text from a linguistic point of view. We would like to thank Serafino Girardi for his vital help in data collection. compression device.

Questionario

\begin{tabular}{|c|c|c|c|c|c|}
\hline Ritiene che i cosciali applicati siano & Per nulla & Poco & Discretamente & Molto & Sopportabili \\
\hline Ritiene che i cosciali applicati siano & Per nulla & Poco & Discretamente & Molto & Causa di insonnia \\
\hline Ritiene che i cosciali applicati siano & Per nulla & Poco & Discretamente & Molto & Rumorosi \\
\hline Ritiene che i cosciali applicati siano & Per nulla & Poco & Discretamente & Molto & Causa di dispnea \\
\hline Ritiene che i cosciali applicati siano & Per nulla & Poco & Discretamente & Molto & Gradevoli \\
\hline Ritiene che i cosciali applicati siano & Per nulla & Poco & Discretamente & Molto & Oppressivi \\
\hline \multicolumn{2}{|c|}{ Si sarebbe fatto togliere i cosciali prima del previsto } & \multicolumn{2}{|c|}{ Si, perchè } & No & \\
\hline
\end{tabular}




\section{References}

1 The Prevention of Venous Thromboembolism (Deep Vein Thrombosis and Pulmonary Embolism) in Patients Undergoing Orthopaedic Surgery and Other High-risk Surgical Procedures. London, National Collaborating Centre for Acute Care, Royal College of Surgeons of England, 2007. http:// www.nice.org.uk/Guidance/CG46.

$\checkmark 2$ Geerts WH, Pineo GF, Heit JA, et al: Prevention of venous thromboembolism: the Seventh ACCP Conference on antithrombotic and thrombolytic therapy. Chest 2004; 126(suppl):338S-400S.

3 Kleinbart J, Williams MV, Rask K: Prevention of venous thromboembolism; in Shojania KG, Duncan BW, McDonald KM, et al (eds): Making Health Care Safer: A Critical Analysis of Patient Safety Practices. Evidence Report/Technology Assessment No. 43. Rockville, Agency for Healthcare Research and Quality, 2001, pp 332-346.

4 Scarpa RM, Carrieri G, Gussoni G, et al: Clinically overt venous thromboembolism after urologic cancer surgery: results from the @RISTOS Study. Eur Urol 2007;51:130136.

5 Soloway MS: Thromboembolism prophylaxis and total prostatectomy: is pharmacologic therapy required? Eur Urol 2008;53:21-23.

6 Kakkos SK, Szendro G, Griffin M, Daskalopoulou SS, Nicolaides AN: The efficacy of the new SCD response compression system in the prevention of venous stasis. J Vasc Surg 2000;32:932-940.

7 Sinclair J, Forbes CD, Prentice CR, Scott R: The incidence of deep vein thrombosis in prostatectomised patients following the administration of the fibrinolytic inhibitor, aminocaproic acid (EACA). Urol Res 1976;4: 129-131.

$\checkmark 8$ Mayo ME, Halil T, Browse NL: The incidence of deep vein thrombosis after prostatectomy. Br J Urol 1971;43:738-742.

$\checkmark 9$ Gordon-Smith IC, Le Quesne LP, Grundy DJ, Newcombe JF, Bramble FJ: Controlled trial of two regimens of subcutaneous heparin in prevention of postoperative deep-vein thrombosis. Lancet 1972; i:1133-1135.

10 Montgomery JS, Wolf JS Jr: Venous thrombosis prophylaxis for urological laparoscopy: fractionated heparin versus sequential compression devices. J Urol 2005; 173:16231626.
11 Galvin DJ, Mulvin D, Quinlan DM: Thromboprophylaxis for radical prostatectomy: a comparative analysis of present practice between the USA, the UK, and Ireland. Prostate 2004;60:338-342.

12 Koch MO, Smith JA Jr: Low molecular weight heparin and radical prostatectomy: a prospective analysis of safety and side effects. Prostate Cancer Prostatic Dis 1997;1:101104.

13 Robertson KA, Bertot AJ, Wolfe MW, Barrack RL: Patient compliance and satisfaction with mechanical devices for preventing deep venous thrombosis after joint replacement. J South Orthop Assoc 2000;9:182-186.

14 Chan JC, Roche SJ, Lenehan B, O'Sullivan M, Kaar K: Compliance and satisfaction with foot compression devices: an orthopaedic perspective. Arch Orthop Trauma Surg 2007; 127:567-571.

$\checkmark 15$ Blanchard J, Meuwly JY, Leyvraz PF, et al: Prevention of deep-vein thrombosis after total knee replacement. Randomised comparison between a low-molecular-weight heparin (nadroparin) and mechanical prophylaxis with a foot-pump system. J Bone Joint Surg Br 1999;81:654-659.

$\checkmark 16$ Pitto RP, Hamer H, Heiss-Dunlop W, Kuehle J: Mechanical prophylaxis of deep-vein thrombosis after total hip replacement a randomised clinical trial. J Bone Joint Surg Br 2004;86:639-642.

17 Wood KB, Kos PB, Abnet JK, Ista C: Prevention of deep-vein thrombosis after major spinal surgery: a comparison study of external devices. J Spinal Disord 1997;10:209-214.

18 Kakkos SK, Caprini JA, Nicolaides AN, Reddy D: Combined modalities in the prevention of venous thromboembolism: a review of the literature. Phlebology 2006;21(suppl 1):23-28.

19 Westrich GH, Rana AJ, Terry MA, Taveras NA, Kapoor K, Helfet DL: Thromboembolic disease prophylaxis in patients with hip fracture: a multimodal approach. J Orthop Trauma 2005; 19:234-240.

20 Westrich GH, Jhon PH, Sánchez PM: Compliance in using a pneumatic compression device after total knee arthroplasty. Am J Orthop 2003;32:135-140.
21 Silbersack Y, Taute BM, Hein W, Podhaisky $\mathrm{H}$ : Prevention of deep-vein thrombosis after total hip and knee replacement. Low-molecular-weight heparin in combination with intermittent pneumatic compression. J Bone Joint Surg Br 2004;86:809-812.

22 Maxwell GL, Synan I, Hayes RP, ClarkePearson DL: Preference and compliance in postoperative thromboembolism prophylaxis among gynecologic oncology patients. Obstet Gynecol 2002;100:451-455.

23 Irwin DE, Milsom I, Hunskaar S, et al: Population-based survey of urinary incontinence, overactive bladder, and other lower urinary tract symptoms in five countries: results of the EPIC study. Eur Urol 2006;50:13061315.

24 Chartier-Kastler E, Chapple CR: LUTS/BPH in clinical practice: the importance of nocturia and quality of sleep. BJU Int 2006;98 (suppl 2):3-8.

25 Savard J, Simard S, Hervouet S, Ivers H, Lacombe L, Fradet Y: Insomnia in men treated with radical prostatectomy for prostate cancer. Psychooncology 2005;14:147-156.

26 Pitto RP, Young S: Foot pumps without graduated compression stockings for prevention of deep-vein thrombosis in total joint replacement: efficacy, safety and patient compliance: a comparative, prospective clinical trial. Int Orthop 2008;32:331-336.

$>27$ Ramirez JI, Vassiliu P, Gonzalez-Ruiz C, et al: Sequential compression devices as prophylaxis for venous thromboembolism in high-risk colorectal surgery patients: reconsidering American Society of Colorectal Surgeons parameters. Am Surg 2003;69:941945.

$\checkmark 28$ Lyman GH, Khorana AA, Falanga A, et al: American Society of Clinical Oncology Guideline: recommendations for venous thromboembolism prophylaxis and treatment in patients with cancer. J Clin Oncol 2007;25:5490-5505.

29 Roderick P, Ferris G, Wilson K, et al: Towards evidence based guidelines for the prevention of venous thromboembolism: systematic reviews of mechanical methods, oral anticoagulation, dextran and regional anaesthesia as thromboprophylaxis. Health Technol Assess 2005;9:iii-iv, ix-x, 1-78. 